\title{
SYNTHESIS, CRYSTAL STRUCTURE AND PHOTOLUMINESCENCE PROPERTIES OF A NEW RARE-EARTH CARBONATE $\mathrm{Na}_{3} \mathrm{Eu}\left(\mathrm{CO}_{3}\right)_{3} \cdot 6 \mathrm{H}_{2} \mathrm{O}$
}

\author{
RONG-HUA ZHANG, DAN ZHAO*, MIN HUANG, RUI-JUAN YANG, FA-XUE MA, YUN-CHANG FAN* \\ College of Chemistry and Chemical Engineering, Henan Polytechnic University, Jiaozuo, Henan 454000, China
}

\begin{abstract}
A new sodium europium carbonate hydrate, $\mathrm{Na}_{3} \mathrm{Eu}\left(\mathrm{CO}_{3}\right)_{3} \cdot 6 \mathrm{H}_{2} \mathrm{O}$, has been prepared using the hydrothermal method, and its structure was determined by single crystal X-Ray diffraction analysis for the first time. It crystallizes in the polar hexagonal space group $P 6_{3}$ with $a=11.382(9) \AA, c=5.989(5) \AA, V=672.06(9)$ $\AA^{3}, Z=2, M r=509.06, D c=2.516 \mathrm{~g} / \mathrm{cm}^{3}, F(000)=492, \mu(\mathrm{MoK} \alpha)=4.84 \mathrm{~mm}^{-1}, R_{1}=0.015$ and $w R=0.038$. The structure features a three-dimensional (3D) framework composed of planar $\left(\mathrm{CO}_{3}\right)^{2-}$ triangles, $\mathrm{Eu}^{3+}$ ions and $\mathrm{Na}^{+}$ions, which delimits $1 \mathrm{D}$ infinite chains with a hexangular star appearance along the $c$-axis. The IR spectrum and the self-activated photoluminescence properties were studied. Under the excitation of near UV light (395nm), it shows strong red emission at 618 $\mathrm{nm}$ with a lifetime of $348.7 \mu \mathrm{s}$. Present research indicates that $\mathrm{Na}_{3} \mathrm{Eu}\left(\mathrm{CO}_{3}\right)_{3} \cdot 6 \mathrm{H}_{2} \mathrm{O}$ is a promising red phosphor for white light-emitting diodes.
\end{abstract}

Keywords: hydrothermal; carbonate; X-ray diffraction; photoluminescence

\section{INTRODUCTION}

In the last few decades, an extensive research has been carried out for new rare earth luminescent materials, owning to their potential applications in optical information transmission, display imaging, solar photovoltaic conversion, fluorescent powder, electrical conduction, new light source and X-ray intensifying screen..$^{1-3} \mathrm{Eu}^{3+}$ ion doped material is an effective red phosphor due to its intense near UV absorption and excellent pure red emissions corresponding to the ${ }^{5} \mathrm{D}_{0} \rightarrow{ }^{7} \mathrm{~F}_{j}(j=1,2,3,4)$ transitions of $\mathrm{Eu}^{3+} \cdot{ }^{4-8} \mathrm{In}$ recent years, a large amount of rare earth carbonates system has been parepared, such as $\mathrm{Na}_{3} \mathrm{Eu}\left(\mathrm{CO}_{3}\right)_{3},{ }^{9} \mathrm{NaLiRe}\left(\mathrm{CO}_{3}\right)_{3}(\mathrm{Re}=\mathrm{Eu}-\mathrm{Er}, \mathrm{Yb}, \mathrm{Lu}, \mathrm{Y}),{ }^{10} \mathrm{Na}_{3} \mathrm{Eu}\left(\mathrm{CO}_{3}\right) \mathrm{F}_{3},{ }^{11}$ $\mathrm{BaEu}\left(\mathrm{CO}_{3}\right)_{2},{ }^{12} \mathrm{Ba}_{3} \mathrm{Eu}\left(\mathrm{CO}_{3}\right)_{2} \mathrm{~F}_{3},{ }^{13} \mathrm{Na}_{3} \mathrm{La}\left(\mathrm{CO}_{3}\right)_{4} \mathrm{~F}: \mathrm{Eu}^{3+12}$ and $\mathrm{KGd}\left(\mathrm{CO}_{3}\right) \mathrm{F}_{2}: \mathrm{Eu}^{3+} \cdot{ }^{34}$ However, there were few reports on their luminescence properties. ${ }^{13} \mathrm{In}$ order to explore a new europium carbonate that might afford red luminescent emission, we started a research using the hydrothermal method and a new alkali sodium europium carbonate hydrate $\mathrm{Na}_{3} \mathrm{Eu}\left(\mathrm{CO}_{3}\right)_{3} \cdot 6 \mathrm{H}_{2} \mathrm{O}$ was successfully prepared. The crystal structure, IR spectrum and photoluminescence properties at room temperature were studied for it.

\section{EXPERIMENTAL}

\subsection{Materials and Methods}

All of the chemicals, $\mathrm{NaCO}_{3}, \mathrm{NaHCO}_{3}, \mathrm{Eu}\left(\mathrm{NO}_{3}\right)_{3} \cdot 6 \mathrm{H}_{2} \mathrm{O}$ were purchased from Shanghai Reagent Factory and were analytically pure without further purification. IR spectra were recorded on a Magna 750 FT-IR spectrometer as $\mathrm{KBr}$ pellets in the range of $4000-400 \mathrm{~cm}^{-1}$. Photoluminescence (PL) properties were performed on EDINBURGHFLS980 fluorescence spectrophotometer.

\section{2 Synthesis}

Single crystal was prepared by the follow procedure: a mixture of $\mathrm{Na}_{2} \mathrm{CO}_{3}$ (0.44 g, $4 \mu \mathrm{mol}), \mathrm{NaHCO}_{3}(0.2 \mathrm{~g}, 2 \mu \mathrm{mol})$ and $\mathrm{Eu}\left(\mathrm{NO}_{3}\right)_{3} \cdot 6 \mathrm{H}_{2} \mathrm{O}\left(0.035 \mathrm{~g}, 0.1^{2}\right.$ $\mu \mathrm{mol}$ ) was dissolved in $2 \mathrm{ml}$ deionized water, which was then placed in a 20 $\mathrm{ml}$ Teflon-lined stainless steel autoclave. The autoclave was sealed and heated at $170{ }^{\circ} \mathrm{C}$ under autogenously pressure for $72 \mathrm{~h}$. After being slowly cooled to room temperature at a rate of $5{ }^{\circ} \mathrm{C} / \mathrm{h}$, colorless needle like crystals were collected by filtration, and washed by distilled water.

\section{2. $3 \mathrm{X}$-ray crystal structure determination}

Single crystal X-Ray diffraction analysis ( $\mathrm{SC}-\mathrm{XRD})$ for $\mathrm{Na}_{3} \mathrm{Eu}\left(\mathrm{CO}_{3}\right)_{3} \cdot 6 \mathrm{H}_{2} \mathrm{O}$ was performed on a Bruker Smart Apex2 CCD diffractometer equipped with a graphite-monochromated Mo- $K \alpha$ radiation $(\lambda=0.71073 \AA)$. An appropriate single crystal $(0.20 \mathrm{~mm} \times 0.05 \mathrm{~mm} \times 0.05 \mathrm{~mm})$ was selected and mounted on a fiberglass. The data was collected by the narrow frame means at $296(2) \mathrm{K}$ with a scan width of $0.5^{\circ}$. After that, the data was scaled for absorption using Apex 2 package. ${ }^{16}$ The crystal structure was solved by a software Shelx-2013 and refined by full matrix least squares on $F^{2}$ with XYZ-centeroids of reflections above $2.0 \sigma(I) .{ }^{17}$ In the structure, all non-hydrogen atoms were refined by harmonic anisotropic atomic displacement parameters (ADP), whereas all hydrogen atoms were located at the geometrically calculated positions, and the thermal parameter was confined to be 0.20 . The final refined solutions obtained were checked with the program $P L A T O N,{ }^{18}$ and no higher symmetry was found. Crystallographic data and structural refinement, the atomic coordinates and thermal parameters are given as supporting information (Tab. S1, S2 and S3). Further details of the crystal structure investigations can be obtained from the Fachin formation szentrum Karlsruhe, 76344 Eggenstein-Leopoldshafen, Germany (fax: (49)7247-808-666; e-mail: crysdata@fiz-karlsruhe.de), on quoting the depository number of CSD 431473.

\section{RESULTS AND DISCUSSION}

\section{1 Crystal structure}

Single-crystal X-Ray diffraction analysis revealed that compound $\mathrm{Na}_{3} \mathrm{Eu}\left(\mathrm{CO}_{3}\right)_{3} \cdot 6 \mathrm{H}_{2} \mathrm{O}$ crystallizes in the hexagonal polar space group $P 6_{3}$, which is different from the other reported sodium europium carbonate ${ }^{19}$ and isotype with yttrium analogy compound $\mathrm{Na}_{3} \mathrm{Y}\left(\mathrm{CO}_{3}\right)_{3} \cdot 6 \mathrm{H}_{2} \mathrm{O} \cdot{ }^{20}$ The structure features a three-dimensional (3D) framework constructed by planar $\left(\mathrm{CO}_{3}\right)^{2-}$ triangles, $\mathrm{Eu}^{3+}$ ions and $\mathrm{Na}^{+}$ions, as shown in Fig. 1. There is one sodium (I) atom, one europium (III) atom, one $\left(\mathrm{CO}_{3}\right)^{2-}$ group and two coordinated water molecules in the asymmetric unit of $\mathrm{Na}_{3} \mathrm{Eu}\left(\mathrm{CO}_{3}\right)_{3} \cdot 6 \mathrm{H}_{2} \mathrm{O}$. Carbon atoms are all surrounded by three atoms, forming near planar triangle $\left(\mathrm{CO}_{3}\right)^{2-}$ groups. The $\mathrm{C}-\mathrm{O}$ bond distances range from $1.271 \AA$ to $1.324 \AA$ and $\mathrm{O}^{-} \mathrm{C}^{3}-\mathrm{O}$ bond angles range from $117.4^{\circ}$ to $123.2^{\circ}$ (Tab. 1 ), which are common values comparing with other reported carbonates. ${ }^{21}$ The $\left(\mathrm{CO}_{3}\right)^{2-}$ groups are isolated from each other and are further connected by $\mathrm{Eu}^{3+}$ ions and $\mathrm{Na}^{+}$ions to form a $3 \mathrm{D}$ structure. Europium atoms reside among $\left(\mathrm{CO}_{3}\right)^{2-}$ groups and are coordinated by six oxygen atoms of three $\left(\mathrm{CO}_{3}\right)^{2-}$ groups and three water molecules, forming distorted $\mathrm{EuO}_{9}$ polyhedra (Fig. 2a). The Eu-O bond distances ranges from $2.421 \AA$ to 2.524 $\AA$, which is comparable with other reported europium oxides. ${ }^{22}$ Sodium atoms are 6-coordinated by six $\mathrm{O}$ atoms from four $\left(\mathrm{CO}_{3}\right)^{2-}$ groups and two water molecules, forming distorted $\mathrm{NaO}_{6}$ octahedra (Fig. 2b). The $\mathrm{Na}-\mathrm{O}$ bond distances range from 2.363 to $2.591 \AA$, with an average value of $2.44 \AA$, which is comparable with other reported sodium oxides. ${ }^{23}$

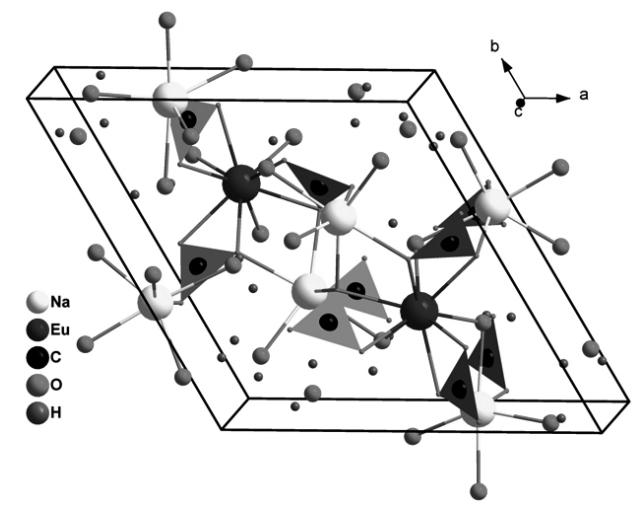

Figure 1. View of the crystal structure of $\mathrm{Na}_{3} \mathrm{Eu}\left(\mathrm{CO}_{3}\right)_{3} \cdot 6 \mathrm{H}_{2} \mathrm{O}$ to show the $\left(\mathrm{CO}_{3}\right)^{2-}$ groups, $\mathrm{Na}^{+}$ions and $\mathrm{Eu}^{3+}$ ions. 
Table1. Selected Bond Lengths $(\AA)$ and Angles $\left({ }^{\circ}\right)$ for $\mathrm{Na}_{3} \mathrm{Eu}\left(\mathrm{CO}_{3}\right)_{3} \cdot 6 \mathrm{H}_{2} \mathrm{O}$

\begin{tabular}{|c|c|c|c|}
\hline $\mathrm{Na} 1-\mathrm{O} 1^{\mathrm{i}}$ & $2.359(4)$ & $\mathrm{Eu} 1-\mathrm{O} 4$ & $2.439(4)$ \\
\hline $\mathrm{Na} 1-\mathrm{O} 2$ & $2.368(3)$ & $\mathrm{Eu} 1-\mathrm{O} 4^{\text {iv }}$ & $2.439(4)$ \\
\hline $\mathrm{Na} 1-\mathrm{O} 5$ & $2.410(5)$ & $\mathrm{Eu} 1-\mathrm{O} 4^{\mathrm{v}}$ & $2.439(4)$ \\
\hline $\mathrm{Na} 1-\mathrm{O} 3^{\mathrm{ii}}$ & $2.437(4)$ & $\mathrm{Eu} 1-\mathrm{O} 2^{\mathrm{v}}$ & $2.524(3)$ \\
\hline $\mathrm{Na} 1-\mathrm{O} 2^{\mathrm{iii}}$ & $2.501(4)$ & $\mathrm{Eu} 1-\mathrm{O} 2^{\mathrm{iv}}$ & $2.524(3)$ \\
\hline $\mathrm{Na} 1-\mathrm{O} 4^{\mathrm{iv}}$ & $2.593(4)$ & $\mathrm{Eu} 1-\mathrm{O} 2$ & $2.524(3)$ \\
\hline $\mathrm{Eu} 1-\mathrm{O} 3^{\mathrm{v}}$ & $2.417(4)$ & $\mathrm{C} 1-\mathrm{O} 1$ & $1.273(5)$ \\
\hline $\mathrm{Eu} 1-\mathrm{O} 3^{\mathrm{iv}}$ & $2.417(4)$ & $\mathrm{C} 1-\mathrm{O} 2$ & $1.284(5)$ \\
\hline $\mathrm{Eu} 1-\mathrm{O} 3$ & $2.417(4)$ & $\mathrm{C} 1-\mathrm{O} 3$ & $1.315(6)$ \\
\hline $\mathrm{O} 1-\mathrm{C} 1-\mathrm{O} 2$ & $123.2(4)$ & $\mathrm{O} 2-\mathrm{C} 1-\mathrm{O} 3$ & $117.2(4)$ \\
\hline $\mathrm{O} 1-\mathrm{C} 1-\mathrm{O} 3$ & $119.6(4)$ & \multicolumn{2}{|l}{} \\
\hline $\mathrm{Sym}$ & & \multicolumn{2}{|l}{} \\
\hline
\end{tabular}

Symmetry codes: (i) $x, y, z-1$; (ii) $x-y+1, x, z-1 / 2$; (iii) $-x+1,-y+1$, $z-1 / 2$; (iv) $-x+y,-x+1, z$; (v) $-y+1, x-y+1, z$; (vi) $x, y, z+1$; (vii) $-x+1$, $-y+1, z+1 / 2$; (viii) $y,-x+y+1, z+1 / 2$. (a)

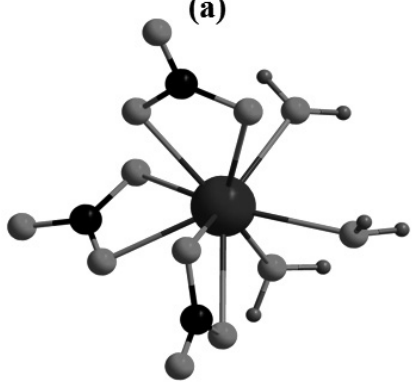

(b)

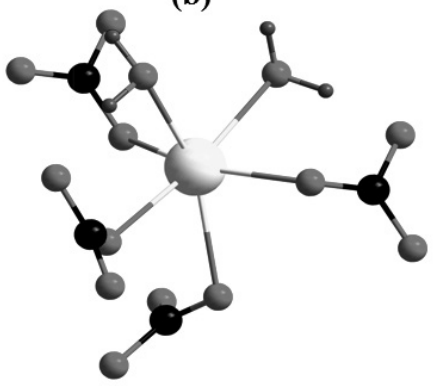

Figure 2. Coordination environments of $\mathrm{Eu}(\mathrm{a})$ and $\mathrm{Na}(\mathrm{b})$ atoms.

The $\mathrm{EuO}_{9}$ groups are isolated from each other and are in linear array along the $c$-axis. In an alternatively view, the $3 \mathrm{D}$ structure of $\mathrm{Na}_{3} \mathrm{Eu}\left(\mathrm{CO}_{3}\right)_{3} \cdot 6 \mathrm{H}_{2} \mathrm{O}$ can be described as $\mathrm{Eu}(\mathrm{III})$ atoms residing among cavities which are delimited by $\left(\mathrm{CO}_{3}\right)^{2-}$ groups and $\mathrm{NaO}_{6}$ octahedra. On the other hand, 1D infinite chains with a hexangular star appearance are delimited in the structure, as shown in Fig. 3.

Bond valence calculation indicates that all atoms are in reasonable oxidation states: +1 for $\mathrm{Na},+3$ for $\mathrm{Eu}$ and +4 for $\mathrm{C}$. The calculated total bond valences for $\mathrm{Na}(1), \mathrm{Eu}(1)$ and $\mathrm{C}(1)$ are 0.976(4), 3.201(11) and 3.93(3), respectively.

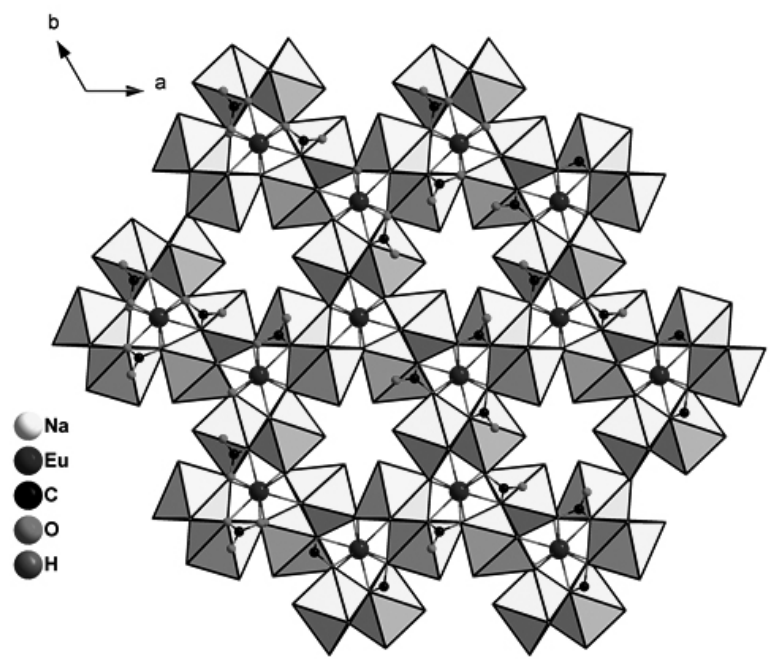

Figure 3. View of the 1D infinite chains with a hexangular star appearance along the c-axis.

\subsection{Infrared spectrum}

Fig. 4 shows the section of the IR spectrum of $\mathrm{Na}_{3} \mathrm{Eu}\left(\mathrm{CO}_{3}\right)_{3} \cdot 6 \mathrm{H}_{2} \mathrm{O}$ from 400 to $4000 \mathrm{~cm}^{-1}$. The IR spectrum exhibits absorptions which are assigned referring to literatures. ${ }^{24}$ The wide and scattered peaks from 3500 to $3000 \mathrm{~cm}^{-1}$ can be attributed to $\mathrm{O}-\mathrm{H}$ stretching vibrations $(\mathrm{O}-\mathrm{H})$ of coordinated water molecules which are intensely affected by hydrogen bonding. ${ }^{25}$ The lattice vibration observed around $415 \mathrm{~cm}^{-1}$ can be assigned to the $\mathrm{Eu}-\mathrm{O}$ stretching vibration, ${ }^{26}$ whereas the vibration of $\mathrm{Eu}-\mathrm{O}$ is very weak and cannot be observed. The main IR absorption region between about 1350 and $1500 \mathrm{~cm}^{-1}$ reveals two absorption bands (1365 and $\left.1520 \mathrm{~cm}^{-1}\right)$ owing to $\mathrm{C}-\mathrm{O}$ stretching vibrations of $\left(\mathrm{CO}_{3}\right)^{2-}$ groups. There is a medium-weak band at $680-775 \mathrm{~cm}^{-1}$, which corresponds to the bending vibration of $\delta$-(OCO) of $\left(\mathrm{CO}_{3}\right)^{2-}$ groups. ${ }^{27}$

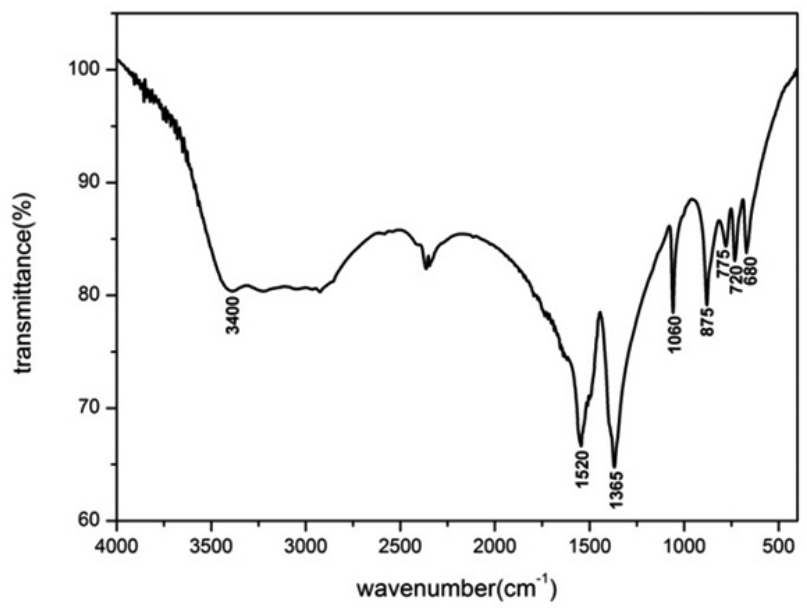

Figure 4. IR spectrum of $\mathrm{Na}_{3} \mathrm{Eu}\left(\mathrm{CO}_{3}\right)_{3} \cdot 6 \mathrm{H}_{2} \mathrm{O}$.

\subsection{Photoluminescence properties}

As shown in Fig. 5a, the photoluminescence (PL) excitation spectrum was recorded from $320-420 \mathrm{~nm}$ by monitoring the most intensity emission at about $618 \mathrm{~nm}$. The excitation spectrum is made up of several sharp peaks that can be assigned to the intrinsic $f \rightarrow f$ transition of Eu ${ }^{3+}$ ions, $361 \mathrm{~nm}$ for ${ }^{7} \mathrm{~F}-{ }^{5} \mathrm{D}, 380 \mathrm{~nm}$ for ${ }^{7} \mathrm{~F}_{0}-{ }^{5} \mathrm{~L}_{8}, 384 \mathrm{~nm}$ for ${ }^{7} \mathrm{~F}_{0}-{ }^{5} \mathrm{~L}_{7}, 395 \mathrm{~nm}$ for ${ }^{7} \mathrm{~F}_{0}-{ }^{5} \mathrm{~L}_{6}$, and $417 \mathrm{~nm}$ for ${ }^{7} \mathrm{~F}_{0}-{ }^{3} \mathrm{D}_{5}$. The highest excitation peak at $395 \mathrm{~nm}$ corresponding to the ${ }^{7} \mathrm{~F}_{0} \rightarrow{ }^{5} \mathrm{~L}_{6}$ transition of $\mathrm{Eu}^{3+}$ matches well with the emission from the near-UV LED chip, implying that the red phosphor $\mathrm{Na}_{3} \mathrm{Eu}\left(\mathrm{CO}_{3}\right)_{3} \cdot 6 \mathrm{H}_{2} \mathrm{O}$ has potential application in white-LED as the red component of tricolor luminescent materials. ${ }^{28}$

As shown in Fig. 5b, the emission spectrum is composed of several distinct groups of sharp lines in the range of 500-750 nm with the most intensive line at $618 \mathrm{~nm}$, which can be assigned to the ${ }^{5} \mathrm{D}_{0} \rightarrow{ }^{7} \mathrm{~F}_{j}(j=0,1,2,3,4)$ transitions of $\mathrm{Eu}^{3+}$ ions. The spectral features of $\mathrm{Eu}^{2+}{ }^{0}$ were not observed, revealing that the europium ions are in the trivalent oxidation state which is in accordance with the crystal structure analysis of $\mathrm{Na}, \mathrm{Eu}\left(\mathrm{CO}_{3}\right)_{3} \cdot 6 \mathrm{H}_{2} \mathrm{O}$. The peaks centered at $591 \mathrm{~nm}$ (orange-red) is caused by the magnetic dipole ${ }^{5} \mathrm{D}_{0} \rightarrow{ }^{7} \mathrm{~F}_{1}$ transition, whereas the most intensive sharp lines centered at $618 \mathrm{~nm}$ (red) are caused by the electric dipole ${ }^{5} \mathrm{D}_{0} \rightarrow \mathrm{F}_{\text {}}$ transition from $\mathrm{Eu}^{3+}$ ions. Other weak emission peaks centered at $536 \mathrm{~nm}, 652 \mathrm{~nm}$ and $696 \mathrm{~nm}$ can be attributed the ${ }^{5} \mathrm{D}_{0} \rightarrow{ }^{7} \mathrm{~F}_{0}$, ${ }^{5} \mathrm{D} \rightarrow{ }^{7} \mathrm{~F}$, and ${ }^{5} \mathrm{D} \rightarrow{ }^{7} \mathrm{~F}$ transitions of $\mathrm{Eu}^{3+}$, respectively. It is well known that the transition intensity is intensely influenced by the external environment of $\mathrm{Eu}^{3+}$ ions. ${ }^{29}$ If $\mathrm{Eu}^{3+}$ ions located in a site with inversion symmetry, the magnetic dipole transition ${ }^{5} \mathrm{D}_{0} \rightarrow{ }^{7} \mathrm{~F}_{1}$ is frequently the strongest one, while in a site without inversion symmetry the ${ }^{5} \mathrm{D}_{0} \rightarrow{ }^{7} \mathrm{~F}_{2}$ electronic transition usually becomes dominant. For $\mathrm{Na}_{3} \mathrm{Eu}\left(\mathrm{CO}_{3}\right)_{3} \cdot 6 \mathrm{H}_{2} \mathrm{O}$, the significantly higher intensity of the ${ }^{5} \mathrm{D}_{0} \rightarrow{ }^{7} \mathrm{~F}_{2}$ transition compared to the ${ }^{5} \mathrm{D}_{0} \rightarrow{ }^{7} \mathrm{~F}_{1}$ transition typically indicates that the $\mathrm{Eu}^{2+}$ sites are not inversion centers and the electric dipole transition ${ }^{5} \mathrm{D}_{0} \rightarrow{ }^{7} \mathrm{~F}_{2}$ is dominant in the host lattice. The result is in accordance with the crystal lattice of $\mathrm{Na}_{3} \mathrm{Eu}\left(\mathrm{CO}_{3}\right) \cdot 6 \mathrm{H}_{2} \mathrm{O}$ which crystallizes in the polar space group $\mathrm{PG}_{3}$ and all atom sites including $\mathrm{Eu}^{3+}$ ions locate in non-centrosymmetric sites.

The decay curve of $\mathrm{Na}_{3} \mathrm{Eu}\left(\mathrm{CO}_{3}\right)_{3} \cdot 6 \mathrm{H}_{2} \mathrm{O}$ with $\lambda=618 \mathrm{~nm}$ and $\lambda=395 \mathrm{~nm}$ was measured, as shown in Fig. 6 . The decay curve can be well fitted with a single-exponential function:

$$
I_{(t)}=I_{0}+A_{1} \exp (-t / \tau)
$$

Where $I_{(t)}$ and $I_{0}$ are the luminescence intensities at time 0 and $t, A_{1}$ is 
the pre-exponential factor obtained from the curve fitting and $\tau$ represents the lifetime of the excited state. The value of $\tau$ is calculated to be $348.7 \mu \mathrm{s}$. It should be noted that there is only one decay phenomenon revealed by the experiment, meaning that the divalent europium is located in only one crystallographic site which is well fitted with the crystal structure analysis.
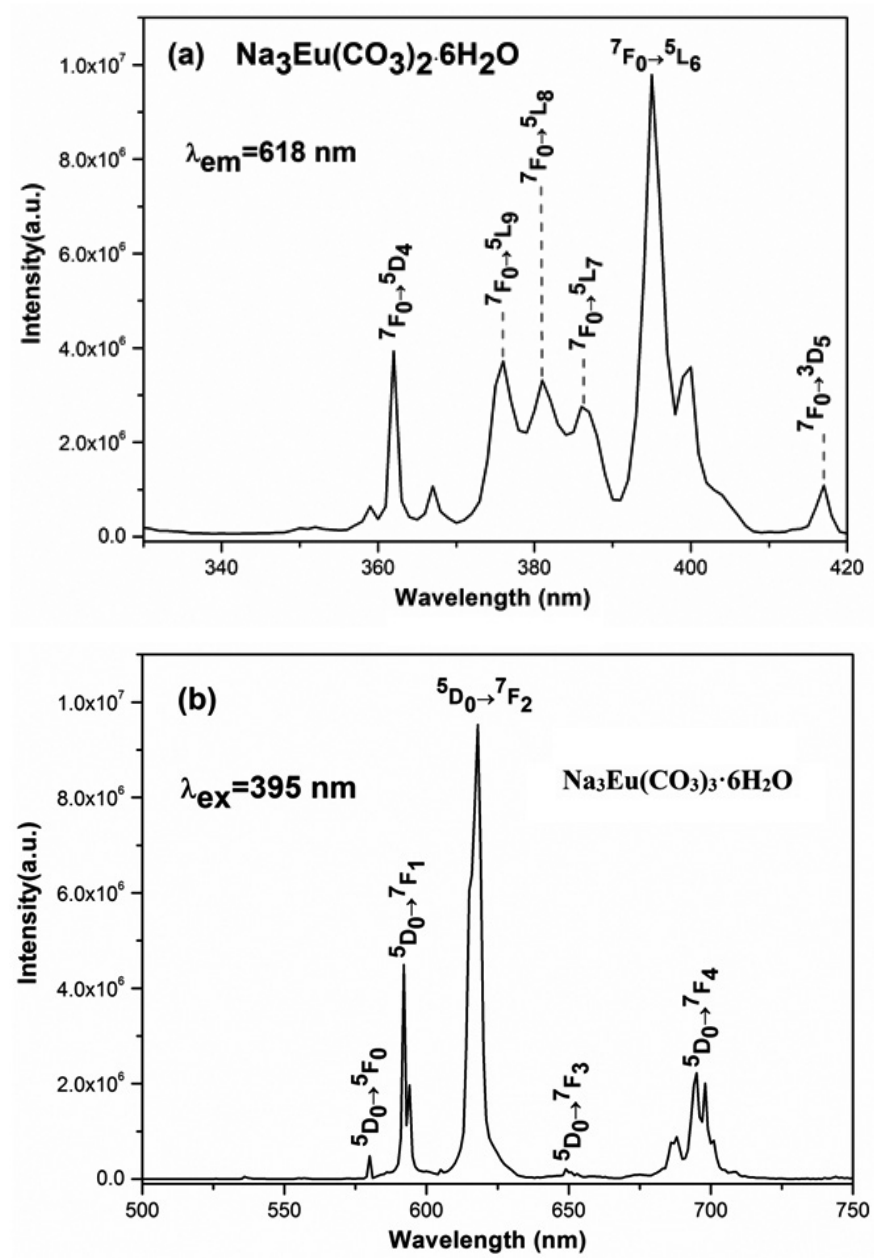

Figure 5. Excition (a) and emission (b) spectra of $\mathrm{Na}_{3} \mathrm{Eu}\left(\mathrm{CO}_{3}\right)_{3} \cdot 6 \mathrm{H}_{2} \mathrm{O}$.

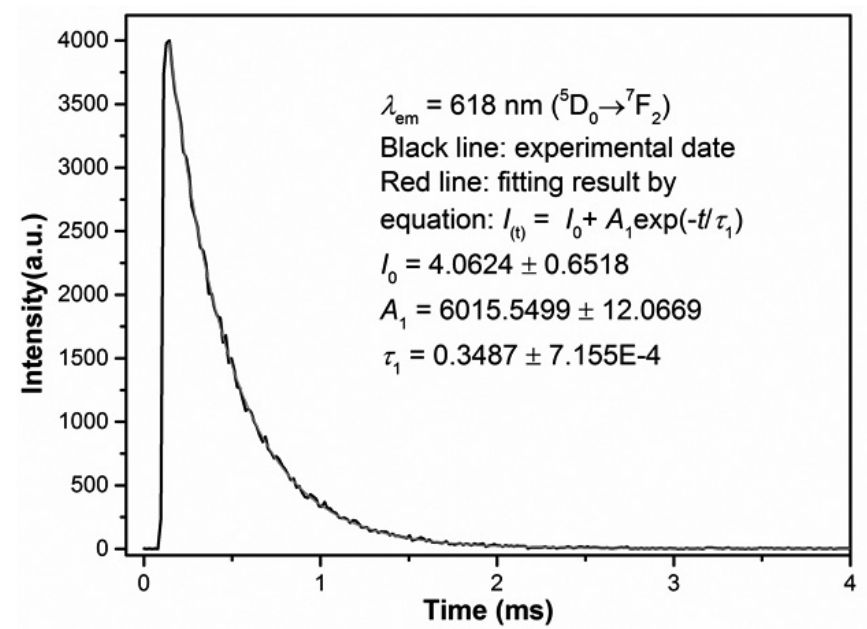

Figure 6. Decay curve of ${ }^{5} \mathrm{D}_{0}-{ }^{7} \mathrm{~F}_{0}$ transition under the excitation of 395 $\mathrm{nm}$ for $\mathrm{Na}_{3} \mathrm{Eu}\left(\mathrm{CO}_{3}\right)_{3} \cdot 6 \mathrm{H}_{2} \mathrm{O}$.
It is well-known that three main colors recognized by the human vision system are red, green and blue. These three colors are usually referred to as the 1931 color coordinates, which is the current standard for lighting specifications on the market. ${ }^{30,31}$ In general, the color of any light source in this color space can be represented as an $(x, y)$ coordinate. The location of the color coordinates of $\mathrm{Na}_{3} \mathrm{Eu}\left(\mathrm{CO}_{3}\right) \cdot 6 \mathrm{H}_{2} \mathrm{O}$ red phosphor on the $\mathrm{CIE}$ chromaticity diagram was presented in Fig. 7. Under the excitation at $395 \mathrm{~nm}$, the calculated CIE chromaticity coordinate is $(0.660,0.340)$, which is very close to the standard red chromaticity coordinates $(0.670,0.330)$ for National Television Standard Committee system (NTSC). We may expect that compound $\mathrm{Na}_{3} \mathrm{Eu}\left(\mathrm{CO}_{3}\right)_{3} \cdot 6 \mathrm{H}_{2} \mathrm{O}$ can be used as a good red phosphor for the three colors white LEDs.

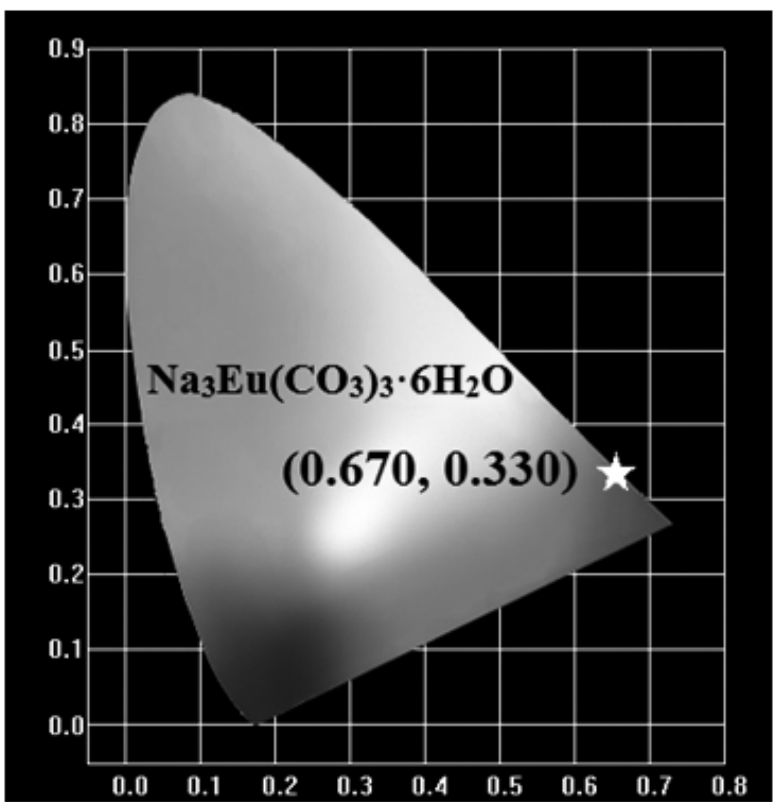

Figure 7. CIE chromatic diagram showing the chromatic coordinates of red phosphor $\mathrm{Na}_{3} \mathrm{Eu}\left(\mathrm{CO}_{3}\right)_{3} \cdot 6 \mathrm{H}_{2} \mathrm{O}$

\section{CONCLUSION}

In the present work, we reported the synthesis, crystal structure, and PL properties of a new sodium europium carbonate hydrate, $\mathrm{Na} 3 \mathrm{Eu}\left(\mathrm{CO}_{3}\right)_{3} \cdot 6 \mathrm{H}_{2} \mathrm{O}$, Its structure features a 3D framework constructed by planar $\left(\mathrm{CO}_{3}\right)^{2-}$ triangles, $\mathrm{Eu}^{3+}$ ions and $\mathrm{Na}^{+}$ions, which delimits 1D infinite chains with a hexangular star appearance along the $c$-axis. Under the excitation of near UV light (395nm), a strong red emission peak centered at $618 \mathrm{~nm}$ can be observed with a lifetime of $348.7 \mu$ s. Meanwhile, the CIE chromaticity coordinates is calculated to be $(0.660,0.340)$. The excitation spectrum covers a wide range from 361 to 417 $\mathrm{nm}$, and matches well with the emissions of near-UV InGaN-based LED chips, making $\mathrm{Na}_{3} \mathrm{Eu}\left(\mathrm{CO}_{3}\right)_{3} \cdot 6 \mathrm{H}_{2} \mathrm{O}$ promising as a red phosphor for efficient excitation by radiation of commercial InGaN based LEDs.

\section{ACKNOWLEDGMENTS}

This work was financially supported by National Science Foundation of China (Grant No.21201056, 21307028).

\section{REFERENCES}

1. D. Wawrzynczyk, M. Samoc, Cryst. Eng. Comm. 17, 1997 (2015).

2. W. Xiao, X. Zhang, Z. Hao, G. H. Pan, Y. Luo, L. Zhang, J. Zhang, Inorg. Chem. 54, 318, (2015).

3. X. Xu, W. Dong, J. Ding, Y. Feng, F. Zhang, L. Ma, Z. J.Peng,Fabrication of $\mathrm{Y}_{3} \mathrm{Al}_{5} \mathrm{O}_{1}: \mathrm{Eu}$ thin films and powders for field emission display applications J. Nanosci. Nanotechnol. 15, 543, (2015).

4. M. Luo, Y. Song, C. Lin, N. Ye, W. Cheng, X. F. Long, Chem. Mater. 28, 2301, (2016)

5. K. V. Raju, C. N. Raju, S. Sailaja, S. J. Dhoble, B. S. Reddy, J. Lumin 134, 297, (2013). 
6. X. Li, L. Guan, M. S. Sun, H. Y. Liu, Z. p. Yang, Q. L. Guo, G. S. Fu, J. Lumin. 131, 1022, (2011).

7. D. Rajesh, M. Dhamodhara Naidu, Y. C. Ratnakaram, J. Phys. Chem. Solids. 75, 1210, (2014)

8. S. Hachani, B. Moine, A. El-akrmi, M. Férid, Opt. Mater. 31, 678, (2009).

9. N. Ye, C. Tu, X. Long, X. Long, Cryst. Growth Des. 10, 4672, (2010).

10. U. Rambabu, S. Buddhudu, Opt. Mater. 17, 401, (2009).

11. M. Luo, N. Ye, G. Zou, C. Lin, W. Cheng, Chem. Mater. 25, 3147, (2009).

12. E. Antic-Fidancev, M. Lemaitre-Blaisd, P. Porcher, N. Mercier, M. Leblanc, J. Solid State Chem. 116, 286, (1995).Optical Properties of $\mathbf{B a E u}\left(\mathbf{C O}_{3}\right)_{2}$ $\mathrm{F}$ and $\mathrm{Na}_{3} \mathrm{La}_{2}\left(\mathrm{CO}_{3}\right)_{4} \mathrm{~F}$ : $\mathrm{Eu}^{3+}$ : Correlations to the Crystallographic Structures

13. N. Mercier, M. Leblanc, F. Antic-Fidaancev, M. Lemaitre-Blaise, P. Porcher, J. Solid State Chem. 132, 33, (1995).

14. N. Mercier, N. Leblanc, E. Antic-Fidancev, M. Lemaitre-Blaise, P. Porcher, J. Alloys Comp. 225, 198, (1995).

15. G. B. Stringfellow, M. G. Craford, Semiconduct. Semimet. 48, 1, (1997).

16. A. Karmakar, I. Goldberg, Cryst. Eng. Comm. 13, 339, (2011).

17. T. Beck, A. Krasauskas, T. Gruene, G. M. Sheldrick, Acta Crystallogr. 64 $1179,(2008)$.
18. G. M. Sheldrick, Acta Crystallogr. A. 4, 12, (2008).

19. J. D. Grice, Can. Mineral. 34, 649, (1996).

20. I. V. Pekov, N. V. Chukanov, N. V. Zubkova, D. A. Ksenofontov, L. Horvath, A. E. Zadov, D. Y. Pushcharovsky, Can. Mineral. 48, 95, (2010).

21. J. D. Grice, J.V. Velthuizen, R. A. Gault, Can. Mineral. 34, 649, (1996).

22. L. Shen, L. Xiao, J. Phys. D: Appl. Phys. 45, 115, (2012).

23. M. Luo, G. Wang, C. Lin, N. Ye, Y. Zhou, W. Cheng, Inorg. Chem. 53, $80,(2014)$

24. A. Jouini, M. Fe'rid, M. Trabelsi-Ayad, Thermochim Acta. 400, 199, (2003).

25. J. Chen, M. Luo, N. Ye, Z. Anorg. Allg. Chem. 641, 460, (2015).

26. J. Niu, J. Zhao, J. Wang, Y. Bo, J. Coord. Chem. 57, 935, (2004).

27. G. Zou, N. Ye, L. Huang, X. Lin, J. Am. Chem. Soc. 133, 20001, (2011).

28. C. C. Lin, R. S. Liu, J. Phys. Chem. Lett. 2, 1268, (2011).

29. Q. Su, H. B. Liang, Li, Y. C. H. He, Y. Lu, H.; J. Li, Y. Tao, J. Lumin. 122, 927, (2007).

30. J. Wang, J. Zhao, J. Niu, Sci. China Ser. B. 48, 343, (2005)

31. G. B. Stringfellow, M. G. Craford, Academic Press. 6, 247, (1997). 